\section{Questión}

Periodismo / Comunicación ISSN 1669-6581
- Av. $44 \mathrm{~N}^{\circ} 676,1^{\circ}$ piso

CP 1900 - La Plata - Argentina

www.perio.unlp.edu.ar/question

Pensar lo Transmedia hoy: hacia una normalización permeable

Matías Mochen - Martín González Frígoli

https://doi.org/10.24215/16696581e361

\title{
Pensar lo Transmedia hoy: Hacia una normalización permeable.
}

\section{Thinking about Transmedia today: Towards permeable normalization.}

\author{
Matías Mochen \\ Profesor Titular de la Cátedra Producción y Edición Transmedia I. \\ Profesor Adjunto de Comunicación Mediática. Investigador categorizado UNLP. \\ matiasmochen@gmail.com

Martín González Frígoli
Doctor en Comunicación.
Director de la Carrera de Posgrado "Especialización en Comunicación Digital" (virtual)
y de la carrera de Grado:
"Tecnicatura en Comunicación Digital".
Profesor Titular de Gestión de la Comunicación Digital.
Prof. Adjunto del Taller de Producción de Mensajes.
mgfrigoli@gmail.com

\section{Palabras clave}

Transmedia - Normalización - Estrategias - Viralización - Globalización

\section{Keywords}

Transmedia - Normalization - Strategies - Viralization - Globalization

Reescribir en estos tiempos pandémicos es realmente un desafío. En principio porque el nuevo desorden de la vida también es desorden en la mente. Igualmente lo estamos haciendo.

Ahora bien, comenzaremos diciendo que la comunicación transmedia no es solo un concepto sino más bien una práctica holística que incluye a todo el sistema de las comunicaciones públicas de una organización, caracterizado principalmente por la integración sinérgica de los mensajes, sean bien de producción programada institucional de carácter formal con todas las otras comunicaciones que los propios públicos "en-redan". 
Estas integraciones no implican que cada mensaje que toca las redes es una alarma para que la organización deba tratar de medir y controlar sus posibles repercusiones sobre la propia estrategia comunicacional. Hablamos aquí de tener en cuenta que una estrategia de comunicación impone hoy la posibilidad de que muchas de nuestras creaciones en términos de contenidos pueden ayudarnos a establecer una nueva y potente relación con nuestros públicos, aprovechando el refuerzo lógico que nos dan las audiencias positivas y el enorme beneficio que nos genera la producción de contenidos editados, resignificados y redistribuidos.

Las audiencias positivas reconocen al productor gusteando, reproduciendo y dando continuidad a los relatos. Así como las agendas de los medios tradicionales pueden aún generar contenidos que tal cual otros textos pueden o no tener desenlaces progresivos, lo mismo sucede cuando algo por algún motivo (creatividad, importancia, relevancia, etc) es incorporado por la cotidianeidad como tema, aunque no necesariamente como acontecimiento. En este contexto de encierro, podemos hacer el ejercicio de imaginar que hay una figura que fue reemplazada.... La hasta hace poco supernaturalizada charla de café, el comentario en la cola del banco, la solución a todo que salía dentro del almacén, etc.

Otros fenómenos interesantes para revisar esas resignificaciones son las nuevas formas de comunicación que se están superponiendo, en apariencia dado que no hemos tenido tiempo de revisar resultados, en tendencia para pensar estos nuevos modos de ser de la construcción del concepto de comunidad (esto será para otra vez).

Cuando los emojis aparecieron como posibilidad de enriquecer los textos informales de nuestras comunicaciones (por ejemplo en un chat telefónico) no pensábamos ni remotamente que eso iba a ser tolerable en cuestiones más serias, como una charla de negocios, y sin embargo ya es tendencia quitarle tensión a una discusión en línea enviando un "sticker", o compartir con clientes un meme o un video que nos cae en gracia y de algún modo nos identifica, generando una relación de cercanía que da nuevos atributos y responsabilidades a las acciones de marca.

La clave de lectura aquí podemos imaginar que está pasando por una necesidad humana de seguir dando orden y regularidad a un mundo más desordenado en términos de input's y output's de información.

Las narrativas y los relatos en todas sus formas mutan casi antes de terminar de ser totalmente incorporadas por los productores y los usuarios, lo que da lugar a una modalidad de trabajo en 
las estrategias de comunicación llamémosle PERMEABLE, sobre todo en el tema de las comunicaciones de marca y el contexto.

\section{Entre el conocimiento y las estrategias de comunicación permeables}

Para comprender mejor esta idea de permeabilidad de las estrategias comunicacionales en contexto de protagonismo de las relaciones digitales, cosa oportuna si se quiere, resulta imprescindible aceptar al conocimiento en general como un conocimiento provisorio, como conocimiento del hasta ahora.

En el marco de esta pandemia podemos atrevernos a pensar brevemente en lo que sucede con ciencias que se soñaron a si mismas como soberanas. Hablamos del derecho, las ciencias económicas, la medicina, etc. Todo lo que manejan hoy son hipótesis. Sino todo, lo máximo que logramos como sociedad es un plan de crisis que está anclado en el desconocimiento y la comunicación. Es decir, cómo la especie mas evolucionada del planeta nuestra estrategia de acción es manejar esta crisis como una gran crisis de comunicación, volvamos a pensarlo un minuto. ¿Qué hicimos?

La comunicación es hoy la herramienta fundamental para combatir el desconocimiento.

Dejemos los detalles sobre el virus a los especialistas. Y volvamos un momento más al tema del conocimiento.

El conocimiento es un conocimiento provisorio, situado, localizado en este aquí y ahora que en términos específicos nos ayuda a dar orden al mundo humano.

Provisorio y adecuado a las demandas de nuestras comunidades, porque el conocimiento es una necesidad básica. Vale de ejemplo siempre una exageración. No podría subir un a escalera si no supiera que me va a sostener y permitir llegar arriba y de vuelta abajo.

Entonces la información con que contamos nos da oportunidad de construir tipos de conocimiento, verdades provisorias que nos sirven para vivir.

Y no solo no escapa a la idea la comunicación estratégica sino que le da sentido. Es clave comprender que lo que hace al mundo humano un mundo dinámico es justo esa provisoriedad. La innovación, el desarrollo productivo, los avances tecnocientíficos son resultante de este movimiento.

El conocimiento comprendido así nos hace permeables al contexto de modo irrevocable. Claramente tenemos por cierto que la tierra gira alrededor del sol. Pero eso ya está. No nos 
significa. Hoy nos significa saber si podremos volver a abrazar a una amigo, o volver a vernos, o saber cómo vamos a retomar nuestras actividades, ir as dar clases, a una asado, volver a las fábricas, viajar, manifestarnos. De lo que nos interesa, lo que sabemos... es por ahora.

Ante los desafíos que nos plantea nuestra disciplina a la hora de meternos al universo de las nuevas tecnologías, debemos intentar comprender los mecanismos socioculturales que entran a dialogar con los avances tecnocientíficos y desde ahí poder generar estrategias de comunicación adecuadas a los objetivos que nos guían y siempre respetando las lógicas propias de cada medio y de nuestros receptores, públicos o audiencias.

El Diseño de estrategias de comunicación ha llegado en nuestros días a ser una de las vedettes de la época, motivada en enorme medida por las posibilidades que la internet le dio a los otros medios, permitiéndoles fusionarse a todos ellos en una megared de informaciones telemáticas instantáneas, donde proliferan todo tipo de conversaciones.

Sin embargo, si nos fijamos con atención, internet, está colmada de espacios que son apenas ventanas estáticas que anuncian poco más que lo que anuncia la guía telefónica, y muchísimas más que se dicen dinámicas por usar flash, pero fueron creados con lógica emisionista y con la misma rutina productiva que una pieza gráfica diseñada sólo para ser leída.

Ineludiblemente, un Proyecto de Comunicación Social, Institucional, Organizacional, Comunitaria, etc., por general y ambigua que parezca la afirmación, ya no procede sin su componente llamado "digital". Asimismo, es momento de llegar a proponer de entrada que el modelo emisionista de la comunicación fue aplastado por la realidad presente y futura de la interactividad, del co-protagonismo de los diferentes actores sociales relacionados en cada conversación, aunque existan millones de referencias que demuestren cómo resisten los poderes hegemónicos mundiales por sostener una cierta linealidad en las comunicaciones públicas. Nomenclaturas y cambios culturales paradigmáticos.

Si pensamos en lo disciplinar, exclusivamente, nuestras nomenclaturas provienen de diversas fuentes. Desde la semiótica, que nos aporta la significación, con perspectivas como las de Peirce o Eco, con conceptos básicos para la interpretación del sentido de los discursos, signo, indice, ícono, símbolo, o la idea del Lector Modelo. Desde la telemática, la ingeniería, conceptos estructurales que sobrevivieron todas las injurias que les propinaron, detestados e inolvidables, emisor, mensaje, receptor, código, canal,...retroalimentación. Le pedimos prestado al marketing, 
a la lingüística, a la sociología, etc. para poder hablar de eso tan dinámico como escurridizo llamado comunicación.

Y mucho decimos, porque sino es imposible explicar nuestro objeto, tomando conceptos de la informática, hoy amiga inseparable luego de la revolución que las Ntics aportaron a nuestras culturas, luego de la generalización del acceso a internet, transformación que alteró todos los paradigmas y creó otros que todavía no podemos dimensionar.

Diseño, plan, programa. Diversas formas para nombrar el aspecto normativo-estructural de una de las disciplinas más nuevas y dinámicas en el vasto campo de las ciencias sociales.

\section{El Aislamiento nos devolvió a McLuhan}

Hace pocos días, intentando dar forma a los acontecimientos y entre las tantas aportaciones que siempre nos genera conversar (esta vez vía telefónica) entre amigos y colegas, uno acertaba en una primera gran afirmación de resume, diciendo que las frases más repetidas al comunicarnos son "hola" y "me estas escuchando?", entendiendo que la conectividad predetermina y condiciona la propia comunicación mediada por cualquier dispositivo.

Fue entonces que comenzamos a preguntarnos cuáles conceptos ya dados por permanentes revalorizaban su sentido en este contexto globalmente particular, en términos comunicaciones y sociales.

Si bien algunos ya los tenemos particularmente internalizados, como el de que los tiempos ya no se miden en términos del cronos tanto como en términos de tasa de transferencia; o como el de que la comunicación digital es la disciplina que será universalmente adoptada por todas las disciplinas como apoyo sine qua non. Para decirlo sin rodeos, en los próximos 10 años no habrá carrera universitaria alguna que no contemple en su currículo al menos una materia sobre comunicación digital.

Otros conceptos, mucho mas de lo deseable, nos resultan tan inestables que al exponerlos a nuestra actual "vida incotidiana" nos interpelan con signo de interrogación.

De esta lista de definiciones en crisis hay algunos sobre los cuales creemos ya tenemos algunas consideraciones que se ajustan mejor a lo que nos está pasando, a saber: Globalización/Viralización; Contacto/Conexión; Globalización/Viralización "El nuestro es un mundo flamante de repentineidad. El "tiempo" ha cesado, el "espacio" se ha esfumado. Ahora vivimos en una aldea global... un suceder simultáneo." Así nos marcó el camino 
Marshall McLuhan (EL MEDIO ES EL MASAGE, 1967) sobre las consecuencias del proceso llamado Globalización.

Convengamos que Foucault nos enseñó el camino de la resignificación, podríamos sentar a McLuhan a que nos aclare un poco el panorama y no tendría inconveniente en llamar a aquella aldea en la que se convertía el mundo por intermedio de las tecnologías, como una aldea viral, donde todo el globo forma parte de lo que sucede sino de todo lo que sucede a nivel viral, a nivel de contagio electrónico, masivo, e inmediato. Como si fuera poco ahora también en términos de pandemia, tanto física como mediática.

Y Marshall arremete con todo asegurando que "hemos tenido que desviar el peso de nuestra atención a la reacción. Ahora debemos conocer de antemano las consecuencias de toda política o acción, ya que experimentamos sus resultados sin demora. Debido a la velocidad eléctrica ya no podemos esperar para ver qué pasa".

Así como si estuviera escribiendo a nuestro lado, pensemos en las estrategias que se están utilizando hoy mismo para que las audiencias no nos condenen, para que en este momento de crisis global/viral los públicos se sumen a las filas de cada uno. Esto cabe tanto para los gobernantes como para las grandes marcas, para contener a los empleados y para la sobrevivencia del comercio del barrio. Insiste McLuhan como si estuviera entre nosotros haciendo la cuarentena, "Con las altas velocidades de la comunicación eléctrica, ya no son posibles los medios puramente visuales de captar el mundo: son demasiado lentos para ser relevantes o eficaces"... y nos deja imaginando qué hubiera pasado si el mundo no hubiera tenido a los medios digitales, (sí también a los médicos y científicos y personal de asistencia y policía, si y GRACIAS por estar ahí) imaginemos este contexto sin estas "prolongaciones de alguna facultad humana, psíquica o física", que son los medios y las nuevas tecnologías.

Para que lean el libro (de a poco que hay tiempo y temas que revisar) imaginen a sus equipos electrónicos y como extienden su cuerpo y sus propias identidades, tanto en lo individual como em lo colectivo, y como eso nos acerca al resto, sin importar la distancia física... inmediatamente.

"Me atrapó el laberinto del engaño

con alas de seda me escapé

cerca de las nubes como en sueños

descubrí que a todos 


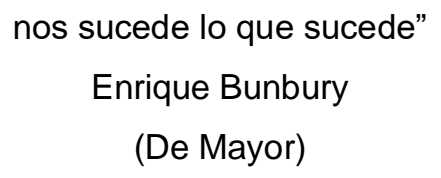

\section{Contacto/Conexión}

Imaginando a las tecnologías como extensiones del cuerpo, McLuhan nos presta otra idea para repensar el hoy, cuando afirma que "todos los medios nos vapulean minuciosamente [...] no dejan parte alguna de nuestra persona intacta [...]. Ninguna comprensión de un cambio social es posible cuando no se conoce la manera en que los medios funcionan de ambientes."

Los medios como ambientes, como lugares de contacto, las tecnologías como posibilidades para conectar cuando no es pensable la conexión física, ni masiva, ni inmediata en otros ambientes. $Y$ la necesidad de concurrir y habitar estos ambientes a través de los relatos, de las narrativas, e incluso cuando solo la función fática de la comunicación (la que solo pretende mantener abierto el canal de la comunicación) son parte central en la basta cantidad de ambientes que irrumpen día a día. "Los ambientes no constituyen envolturas pasivas sino, más bien, procesos activos invisibles [...] La interacción entre los ambientes nuevos y viejos crea muchos problemas y confusiones". Podemos ejemplificar las fragmentaciones selectivas que generan los algoritmos de búsquedas o los bots (como Siri) que contribuyen a generar nuevos ambientes en relación directa a nuestras propias interacciones digitales. Vivimos relacionados en estos micro-mesomacro comunidades, día a día más endogámicas y sinérgicas.

Aunque parezca un escenario apocalíptico, para nuestra vida cotidiana nos resultan sumamente prácticos, ya que no solo sirven a las organizaciones para encontrar públicos usuarios o clientes sino que nos hacen más fáciles las tareas de la cotidianeidad, desde el autorrelleno de los formularios hasta las compras del supermercado (con memoria de la lista de la compra pasada incluída y la entrega a domicilio).

Grandes, enormes masas de información que son filtradas y servidas en nuestras bandejas de entrada, si servidas en bandeja bajo la forma de "notificaciones" o de "resultados" instantáneamente descartan por nosotros la información que no se adecúa a nuestros perfiles. Ya no encontramos lo que buscamos, o lo que nos gusta buscar, lo que buscamos nos encuentra y nos gusta de manera casi mágica. $Y$ si deja de gustarnos lo que sucede es que también eso comienza a desaparecer de nuestros entornos digitales y de nuestras pantallas. Sin nuestra 
interacción eso que me busca dejará de hacerlo, desaparecerá para mí. Lo mismo sucede con las comunidades, donde los seguidores, incluso los heaters forman parte (por interacción) que son ambientes en si mismas y que se alimentan transmedialmente, reasignando a los diferentes medios más la condición de un ambiente de cultivo que de un sustrato, ya que una vez que la comunidad toma forma (siempre provisoria y atentada por la naturales entrópica de la comunicación) puede alterar sus espacios de interacción casi de modo impredecible.

En este sentido, vale discriminar el contacto con la conexión. Podemos estar en contacto y conectados en un punto literalmente tecnológico, sin por ello estar conectados. Tanto las instituciones como las personas, las marcas como los programas pueden tener mayor o menos alcance, y mayor o menor conexión (en términos de identificación) con sus públicos audiencias seguidores etc.-

Una marca puede tener una estrategia de promoción de gran alcance, con un público amplio y hasta con buenos resultados en términos de consumo por su propio prestigio institucional, y sin embargo no tener comunidades que le sean fieles en lo referido al mundo digital.

Esto se da porque la conexión primaria (la tecnológica) permite la posibilidad del contacto (el tecnológico) pero no tendrá cómo llegar a tener un contacto (relacional) sin antes tener una conexión (relacional), una relación de continuidad y de intercambio. Ya no basta con alcanzar grandes cantidades de visitas, vistas o likes. Recién ahí comienza el desafío de construir una relación duradera, imposible sin la complicidad de nuestras audiencias, transformadas en seguidores activos, hechos familia, comunidad.

Es ahí donde los relatos y las narrativas, de líneas tan difusas que casi podemos usarlos como sinónimos, que se han transformado en los grandes protagonistas de nuestras estrategias. Más importante que aparecer ante los públicos, es tener algo que compartir con ellos que ellos quieran compartir con nosotros.

Cuando la publicidad hurga en nuestras ansiedades con unas propuestas de mundo inteligibles, inmediatas y adaptadas a nuestros propios mundos en busca de esa identificación, está tratando de leer los nuevos ambientes que emergen a diario ".... resulta evidente en el famoso relato sobre la vestidura del rey. Los cortesanos "bien adaptados", con sus intereses creados, vieron al emperador magníficamente engalanado. El negro caballerizo "antisocial", no habituado al viejo ambiente vio con claridad que el rey "iba desnudo".". El nuevo ambiente era claramente visible para él. 
Otra disciplina antiambiental es el humor. Hoy las sociedades prosperan con tranquilidad sobre tramas puramente literarias, reclamando líneas narrativas que mientras los medios tradicionales se dedican a digerir las informaciones para servir en bandeja a (sus) audiencias para intentar sobrevivir ante los nuevos medios. El humor en cambio carece de linealidad narrativa, se posa en el árbol por un momento sin nada que le obligue a permanecer allí, es decir se propone como una superposición condensadas de narraciones. Esa incomodidad le permite leer un nuevo ambiente casi de modo inmediato.

Analicemos brevemente la relación entre las juventudes y el mundo adulto. Alguna vez, una docente contó una anécdota sobre comunicación alternativa para lograr que en una zona rural se pudieran separar las distancia entre las letrinas y los pozos de agua en función de prevenir enfermedades por la contaminanción del agua. Luego del fracaso por intentar convencer a los adultos (mayoritariamente no alfabetizados) yendo a visitar los hogares e intentar convencerles de separar los pozos, encontraron una alternativa. Agregaron un módulo en las escuelas donde entre sus contenidos incluyeron la separación de los pozos para impedir la contaminación del agua. $Y$ fueron los estudiantes quienes inocularon en el viejo ambiente la nueva práctica. La relación de poder del saber del viejo ambiente desde las juventudes hacia el mundo adulto había creado un nuevo ambiente.

Parecido fue el movimiento cuando las tecnologías de entretenimiento permitieron que los videojuegos ingresen a los hogares. Pensemos cómo las consolas de videojuegos y las computadoras de escritorio (aún hoy) colocaron a niños y jóvenes en una posición de poder de voz en las casas al enseñar a sus adultos a interactuar con esas tecnologías. Muchos de nosotros le enseñamos a nuestros padres y a nuestras madres a utilizar sus correos electrónicos, si ellos (el mundo adulto) nos ayudaron a aprender a leer, escribir y jugar juegos de mesa, nosotros les enseñamos a configurar sus celulares.

Así llegamos hoy a un nuevo ambiente, contextualizado por el encierro. Nuestros hijos y nuestras hijas ya venían acostumbrados a relacionarse con sus pares a través de las tecnologías digitales. Hasta hace pocos meses, nuestras hijas y nuestros hijos salían de las escuelas y seguían vinculados a través de sus pantallas con una naturalidad que les permitió en este contexto de aislamiento no sentirse tan aislados, porque no están aislados, están conectados relacionalmente. El mundo adulto debío acelerar sus tiempos de adaptación a estos modos de contacto que les permitiera, que nos permitiera, mantenernos conectados. 
Las juventudes nos prestaron sus modos de comunicación y sus ambientes para permitirnos achicar tiempos que de otro modo no podrían explicarse. Así aparecen abuelos y abuelas haciendo videollamadas y bailando junto a sus nietos y nietas a kilómetros de distancia, abuelas aceptando los desafíos (challenges) o ridiculizándose con los mas chiquitos tratando de imitar las coreografías de BTS. El viejo Musical.ly (lanzado en agosto de 2014), hoy conocido (después de su compra y fusión en 2017) como TIK TOK fusionó entretenimiento, humor y contención social. 